\title{
Terpenoid Compounds in the Latex of Euphorbia Azorica from Azores
}

\author{
Elisabete Lima $^{1,2 *}$ and Jorge Medeiros ${ }^{1}$ \\ ${ }^{1}$ Department of Physics, Chemistry and Engineering (DCFQE) and Biotechnology Centre of Azores (CBA), Portugal \\ ${ }^{2}$ Institute of Agricultural and Environmental Research and Technology (IITAA), Portugal
}

*Corresponding author: Elisabete Lima, Department of Physics, Chemistry and Engineering (DCFQE) and Biotechnology Centre of Azores (CBA), University of Azores, 9500-321 Ponta Delgada, São Miguel, Azores, Portugal

\begin{tabular}{l} 
ARTICLE INFO \\
\hline Received: 幽 February 21, 2020 \\
Published: 幽 February 28, 2020 \\
\hline
\end{tabular}

Citation: Elisabete L and Jorge M. Terpenoid Compounds in the Latex of Euphorbia Azorica from Azores. Biomed J Sci \& Tech Res 26(1)-2020. BJSTR. MS.ID.004303.

\begin{abstract}
Plants of Euphorbia genus are well known for their irritant milky latex rich in bioactive terpenoids and their use in traditional medicine worldwide for treatment of several diseases, including cancer that is the second leading cause of death in the world. This research evaluates, for the first time, the major terpenoid compounds from the latex of Azorean E. azorica. Five triterpene alcohols of the euphane, lanostane and cycloartane-type skeleton (namely euphol, obtusifoliol, lanosterol, cycloartenol and 24-methylenecycloartenol) were isolated from the n-hexane fraction. In addition, the diterpene alcohol ingenol was obtained from the ether fraction following to alkaline hydrolysis, which indicates the presence of potential bioactive ingenane diterpenoid esters. Their structures were elucidated by physical, chemical and spectroscopic methods (1H NMR, 13C NMR, IR and mass spectra) and comparison with literature data. The referred triterpenols have been recently reported to possess anti-inflamatory and/ or antitumor activities. Furthermore, ingenol constitutes the core of a recently approved anticancer drug. Thus, the terpenoid composition of E. azorica latex may indicate their chemopreventive and chemotherapeutic potentials on anticancer strategies, which should be investigated.
\end{abstract}

Keywords: Bioactive Natural Products; Euphorbia; Latex; Tetracyclic triterpenes; Euphol; Tetracyclic diterpenes; Ingenol; Anticancer

\section{Short Communication}

Euphorbia (Euphorbiaceae), commonly named spurge, is among the largest genera of Angiosperms, comprising about 2000 species that are characterized by specialized inflorescences (cyathia) and by a caustic and toxic milky latex, which plays defensive roles against herbivores and pathogens. Its worldwide distribution, remarkably diverse growth forms and traditional medicine use have attracted human interest since ancient times. In fact, the genus Euphorbia is of great importance to researchers and pharmaceutical industries due to their numerous medicinal uses attributed to its richness in valuable bioactive metabolites that could provide a reservoir for drug discovery [1]. Euphorbia species, and particularly its latex, are well known to produce a large variety of diterpenoid and triterpenoid compounds that show anticancer and chemopreventive properties as well as ant-inflammatory, antioxidative, antiviral, antibacterial and antifungal ones [1-3].

A good example could be the diterpene ingenol mebutate, isolated from the latex of E. peplus (subgenera Esula), that is the active principle of the new drug Picato for topical treatment of actinic keratosis, a common skin lesion in adults which usually occurs on chronically photoexposed areas and considered as a precancerous lesion or a superficial squamous-cell carcinoma [4]. Also, triterpenic compounds found in latex, including euphane, lanostane and cycloartane-types, can become an alternative method for treating cancer because of their cytotoxic properties and chemopreventive activities [3,5]. As a part of our continuing phytochemical investigation of Azorean plants and also to extend the knowledge towards the Euphorbia species [6], the present study 
aimed at the isolation and characterization of major terpenoid compounds from the latex produced by E. azorica (subgenera Esula), which causes irritation of the skin and eyes, as other Euphorbia species. No studies on the chemistry or pharmacology bioactivity of this species have been published.

\section{Materials and Methods}

\section{General Experimental Procedures}

Melting points (uncorr.) were determined on an Electrothermal IA 8103 apparatus. Optical rotations were measured in $\mathrm{CHCl} 3$ with a Perkin-Elmer 243S polarimeter. IR spectra were recorded on a Perkin-Elmer 1600 FTIR spectrometer with KBr discs. 1H NMR (300.13 MHz) and 13C NMR (75.47 MHz) spectra were measured on a Bruker AMX-300 spectrometer with TMS as internal standard and $\mathrm{CDCl} 3$ as solvent. The number of attached protons for $13 \mathrm{C}$ signals was determined using the DEPT pulse sequence. EIMS $(70 \mathrm{eV})$ was carried out on a VG Auto Spec Q instrument. GC analysis was carried out with a Hewlett-Packard 5890A gas chromatograph equipped with a FID detector (column, OV-101, $15 \mathrm{~m} \times 0.33 \mathrm{~mm} \times$ $0.18 \mu \mathrm{m}$; carrier gas, $\mathrm{N} 2$ at $30 \mathrm{~mL} / \mathrm{min}$; temp. program, $180 \mathrm{oC}$ to $240 \mathrm{oC}$ at $5 \mathrm{oC} / \mathrm{min}$; injection and detection temp., $300 \mathrm{oC})$. The chromatograms were recorded according to the retention time (Rt), and the individual peaks were assigned by Rt based on comparison with authentic standards and/or by spiking the sample with standard. GC/MS analysis was carried out on a Carlo Erba 6000 GC interfaced with a Finnigan-MAT 800 ITD (column, DB-1, 30m x $0.25 \mathrm{~mm}$ x $0.25 \mu \mathrm{m} ; 70 \mathrm{eV} ; 300^{\circ} \mathrm{C}$ ). Column chromatography (CC) was carried out on silica gel 60 (230-400 mesh, Merck) and 20\% AgNO3/silica gel 60 (Merck). TLC was performed on silica gel 60 F254 +366 plates $(0.2$ and $0.5 \mathrm{~mm}$ thicknesses, Merck) and silicagel 60 F254 plates $(0.5 \mathrm{~mm}$, Merck) impregnate with 20\% AgNO3. Acetilation with Ac20/pyridine was carried out in order to convert the natural alcohols into the corresponding acetates. Hydrolysis of diterpenoid esters was carried out according to the procedure described by Lima, et al. [2].

\section{Sample Collection and Fractionation}

One hundred mL of latex was collected from E. azorica Hochst. ex Seub. (from Sao Miguel Island, Azores, Portugal) in an equal volume of $\mathrm{MeOH}$ yielding a ppt. that was separated by decantation and then exhaustively extracted with $\mathrm{Me} 2 \mathrm{CO}$ at room temperature. The combined extracts (11g) were suspended in $85 \%$ aq. $\mathrm{MeOH}$ and partitioned with $n$-hexane to give a non-polar residue of $5 \mathrm{~g}$. The hydroalcoholic residue was partitioned between water and ether (1:1), with the latter residue yielding 910mg. An aliquot (819mg) was hydrolyzed and then extracted with $\mathrm{CH} 2 \mathrm{Cl} 2$ yielding a residue of $245 \mathrm{mg}$.

\section{Isolation of Tetracyclic Triterpenes from The $\mathrm{N}$-Hexane Extract}

The n-hexane extract $(5 \mathrm{~g})$ was subjected to $\mathrm{CC}$ on silica gel
$(150 \mathrm{~g})$ using a gradient of $\mathrm{n}$-hexane-EtOAc. The 80 eluated fractions of $50 \mathrm{~mL}$ were combined in five fractions (A-E). Fraction B (nos. 1929; 0.5g; n-hexane-EtOAc, 98:2; white powder) was acetylated and then dissolved in hot Me2CO. On cooling, the ppt. was filtered off (18mg) and was identified as euphol acetate (Rt $14.05 \mathrm{~min}$ ). The mother liquor was conc. yielding a white powder (100mg) that was purified by prep. TLC on 20\% AgNO3/silica gel 60 plate eluted with chloroform-ether $(95: 5)$ to give $60 \mathrm{mg}$ of obtusifoliol acetate (Rt 14.36 min). Fraction C (nos. 30-42; 2.5g; n-hexane-EtOAc, 97:3; white powder) was acetylated yielding $2 \mathrm{~g}$. An aliquot $(0.5 \mathrm{~g})$ was subjected to CC on 20\% AgNO3/silica gel 60 (50g) eluted with chloroform-ether (95:5). The 80 eluated fractions of $5 \mathrm{~mL}$ were combined in five fractions (C1-C5). Fraction C2 (nos. 13-30; 50mg) was recrystallized from $\mathrm{Me} 2 \mathrm{CO}$ to give $20 \mathrm{mg}$ of lanosterol acetate (Rt $14.81 \mathrm{~min}, \mathrm{mp} 129-131^{\circ} \mathrm{C}$ ), fraction C3 (nos. 31-50; 100mg) was recrystallized from $\mathrm{Me} 2 \mathrm{CO}$ to give $45 \mathrm{mg}$ of cycloartenol acetate (Rt $15.53 \mathrm{~min}, \mathrm{mp} 119-120^{\circ} \mathrm{C}$ ) and fraction C5 (nos. 66$80 ; 40 \mathrm{mg}$ ) was recrystallized from $\mathrm{Me} 2 \mathrm{CO} / \mathrm{MeOH}$ to give $24 \mathrm{mg}$ of 24-methylenecycloartanol acetate (Rt $16.18 \mathrm{~min}, \mathrm{mp} 115-117^{\circ} \mathrm{C}$ ).

\section{Isolation of the Tetracyclic Diterpene Alcohol Ingenol from Ether Extract}

The hydrolysate $(245 \mathrm{mg}$ ) from the ether extract, obtained of the hydroalcoholic residue, was acetylated and then purified by prep. TLC on silica gel 60 plate eluted with chloroform-ether (95:5), yielding an amorphous solid (Rf 0.44 ) that was recrystallized from $\mathrm{MeOH}$ to give $25 \mathrm{mg}$ of ingenol triacetate (Rt $16.52 \mathrm{~min}$, mp 195$\left.197^{\circ} \mathrm{C}\right)$.

\section{Results and Discussion}

This research evaluates the major terpenoid compounds from the latex of E. azorica, endemic to the archipelago of Azores. Five triterpenols (euphol, obtusifoliol, lanosterol, cycloartenol and 24-methylenecycloartenol) were isolated from the n-hexane fraction, obtained of the acetone extract of the latex by partition in n-hexane/85\% aq. $\mathrm{MeOH}$. In addition, ingenol was isolated from the ether fraction, obtained of the hydroalcoholic residue by partition between water and ether (1:1), following to hydrolysis. Thus, this screening procedure, involving hydrolysis, as referred, followed by acetylation and GC analysis of the products, revealed the potential occurrence of ingenane-type esters in the latex of E. azorica, which may contributes to its irritant action on skin and eyes. The structures of the isolated compounds were elucidated by physical, chemical and spectroscopic methods, and comparison with literature data [2]. The above referred tetracyclic triterpenes have been reported to possess anti-inflamatory and/or antitumor activities in vitro and in vivo studies [7-10], presenting euphol the most potent effects among the tested compounds with several reports suggesting this compound as a novel potent antineoplastic agent, namely for glioblastoma that is the most frequent and aggressive type of brain tumor [11]. Furthermore, ingenol constitutes the core of a recently 
approved anticancer drug for topical treatment of actinic keratosis [3]. Thus, the terpenoid composition of E. azorica latex may indicate their chemopreventive and chemotherapeutic potentials that should be investigated.

\section{Conclusion}

Plants from Euphorbia genus are highly reputed for their use in medicine to treat several illnesses, including cancer that was responsible for 9.6 million deaths in 2018, and is expected to rise in the coming decades according to estimates from WHO. The medicinal value of these plants has been mainly attributed to the presence of unique terpenoid metabolites. In this study, the latex of Azorean E. azorica has been reported, for the first time, to contain several known nonpolar bioactive triterpenoids, such as euphol (a potential novel anticancer drug), together with ingenane derivatives (not identified). A more detailed investigation on the phytochemical profile of the latex of E. azorica is needed, together with biological activity studies in order to evaluate its value as a source of natural products of pharmaceutical interest or industrial application, such as crude extracts and its fractions or pure compounds.

\section{Conflict of Interest}

The authors declare no conflicts of interest.

\section{References}

1. Ernst M, Grace OM, Saslis Lagoudakis CH, Nilsson N, Simonsen HT, et al. (2015) Global medicinal uses of Euphorbia L. (Euphorbiaceae). Journal of Ethnopharmacology 176: 90-101.

\section{ISSN: 2574-1241}

DOI: $10.26717 /$ BJSTR.2020.26.004303

Elisabete Lima. Biomed J Sci \& Tech Res

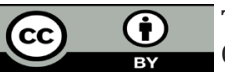

This work is licensed under Creative Commons Attribution 4.0 License

Submission Link: https://biomedres.us/submit-manuscript.php
2. Lima EMC (2000) Estudo fitoquímico de cinco espécies do género Euphorbia: E. stygiana Watson, E. azorica Seubert, E. peplus L., E. mellifera Ait. e E. piscatoria Ait.. Doctoral thesis, Univiversity of Azores, Azores.

3. Chudzik M, Korzonek Szlacheta I, Król W (2015) Triterpenes as potentially cytotoxic compounds. Molecules 20: 1610-1625.

4. Collier NJ, Ali FR, Lear JT (2014) Ingenol mebutate: a novel treatment for actinic keratosis. Clinical Practice 11: 295-306.

5. Aleksandrov M, Maksimova V, Koleva GL (2019) Review of the anticancer and cytotoxic activity of some species from genus Euphorbia. Agriculturae Conspectus Scientificus 84(1): 1-5.

6. Lima EM, Medeiros JM, Davin LB (2003) Pentacyclic triterpenes from Euphorbia stygiana. Phytochemistry 63(4): 421-425.

7. Canelón DJ, Suárez AI, De Sanctis J, Mijares R, Compagnone RS (2008) New antiinflammatory cycloart-23-ene-3 $\beta$-ol from Senefelderopsis chibiriquetensis. Natural Product Communications 3.

8. Baniadam S, Rahiminejad MR, Ghannadian M, Saeidi H, Ayatollahi AM, et al. (2014) Cycloartane triterpenoids from Euphorbia macrostegia with their cytotoxicity against MDA-MB48 and MCF-7 cancer cell lines. Iranian Journal of Pharmaceutical Research 13(1): 135-141.

9. Silva VAO, Rosa MN, Tansini A, Oliveira RJS, Martinho O, et al. (2018) In vitro screening of cytotoxic activity of euphol from Euphorbia tirucalli on a large panel of human cancer-derived cell lines. Experimental and Therapeutic Medicine 16(2): 557-566.

10. Sun Yi, Gao LL, Tang MY, Feng BM, Pei YH, et al. (2018) Triterpenoids from Euphorbia maculata and their anti-inflammatory effects. Molecules 23(9): 2112.

11. Silva VAO, Rosa MN, Miranda Gonçalves V, Costa AM, A Tansini, et al. (2018) Euphol, a tetracyclic triterpene, from Euphorbia tirucalli induces autophagy and sensitizes temozolomide cytotoxicity on glioblastoma cells. Investigational New Drugs 37(2): 223-237.

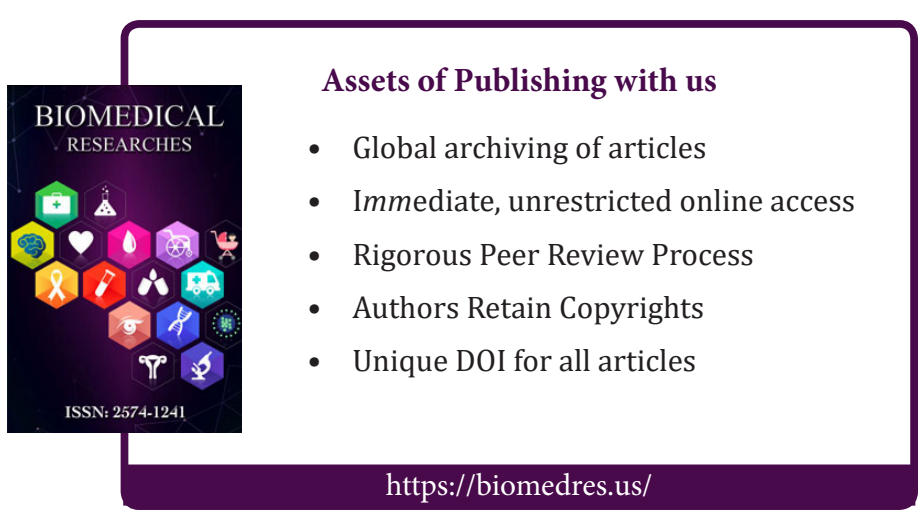

